\title{
Research on the Impact of Interest Rate Liberalization on the Profitability of China's Listed Small and Medium Sized Commercial Banks
}

\author{
Ren Ya \\ School of Economics, Shanghai University, Shanghai, China
}

Email address:

123134277@qq.com

\section{To cite this article:}

Ren Ya. Research on the Impact of Interest Rate Liberalization on the Profitability of China's Listed Small and Medium Sized Commercial Banks.Science Innovation.Vol. 4, No. 4, 2016, pp. 211-215. doi: 10.11648/j.si.20160404.17

Received: August 19, 2016; Accepted: October 12, 2016; Published: October 13, 2016

\begin{abstract}
In 1996, The People's Bank of China (PBOC) established a national treasury bonds market and inter-bank lending market, marking that the official start of China's interest rateliberalization. After 20 years of orderly developing, reform has entered the key stage. In October 23, 2015, the PBOC announced that it would no longer set the floating ceiling of deposit rate to commercial banks and rural cooperative financial institutions. Release the control of interest rate means that the entire banking industry will fall into a more intense competition, and the traditional mode of operation will suffer from more threats and challenges. Especially in China's small and mediumsized commercial banks, compared to the large state-owned banks, the capital accumulation is relatively weak, more limited business development, limited customer resources, lack of brand effect, so it is bound to face more difficulties.In empirical research, the article selects 11 listed small and mediumsized banks as the research samples, using panel data model to analyze how the interest rate liberalization impact the profitability of these selected banks. Finally, combining with analysis results, the article proposes some measures to increasing the profit space of small and mediumsized commercial banks under the process of interest rate liberalization.
\end{abstract}

Keywords: Small and Medium Sized Commercial Banks, Interest Rate Liberalization, Profitability, Panel Data

\section{利率市场化对中国上市中小商业银行盈利能力影响的研究}

\section{任娅}

经济学院, 上海大学, 上海, 中国

邮箱

123134277@qq.com

摘要: 中国的利率市场化改革始于1996年人民银行建立全国统一的国债市场和拆借市场, 经过20年的有序推进, 改革 已经进入了最后的阶段。2015年10月23日央行宣布取消商业银行和农村合作金融机构的存款利率浮动上限，放开存款 利率管制意味着整个银行业将陷入更激烈的竞争, 传统的经营模式将会受到威胁与挑战。尤其是我国的中小商业银行, 其自身资本积累相对薄弱, 业务开展较多地受到地域限制, 客户资源有限, 市场竞争力不足, 所以将会面临更多的困 境。本文运用 Eviews8.0 软件, 建立面板数据模型, 对2008年--2015年我国11家上市中小商业银行的年度数据进行实 证分析。最后根据分析结果，对如何提高中小商业银行的盈利空间提出了相关切实可行的建议。

关键词：中小商业银行, 利率市场化, 盈利能力, 面板数据 


\section{1. 引言}

\section{1. 研究背景及意义}

利率作为要素市场的重要价格, 是效配置资金的决定 性因素，因此，利率市场化改革是中国金融体制改革的核 心环节之一。[1] 2015年10月23日中国人民银行宣布不再 对商业银行和农村合作金融机构等设置存款利率浮动上 限, 并指出未来要抓紧完善利率的市场化形成和调控机制, 标志着我国利率市场化改革进入最后的关键阶段。

随着改革的深入, 利率变动将会更加频繁且难以预测, 不断收窄的存贷款利息差将会给商业银行的运营带来重 大影响。相对于大型商业银行, 我国中小商业银行的资本 积累薄弱, 业务开展也受到较多方面的限制, 必将面临更 多的困境。本文通过面板数据模型, 对中小商业银行的盈 利能力在利率市场化进程中的变化进行分析, 并提出相应 的对策和建议。

\section{2. 我国利率市场化现状}

[2]我国的利率市场化改革始于1996年，在经历了拆 借利率、债券利率、外币利率和人民币贷款利率的市场化 之后, 自2014年起, 我国的存款利率市场化进程明显提速。 金融机构存款利率浮动上限从 1.1 倍扩大到 2015 年 5 月的 1.5 倍。2015年8月，央行放开了一年期以上（不含一年） 定期存款的利率浮动上限。2015年10月24日, 央行再次下 调存贷款基准利率，并取消了对商业银行和农村合作金融 机构的存款利率浮动上限。截止2016年3月24日, 我国部 分商业银行各档期存款利率水平如下:

\begin{tabular}{|c|c|c|c|c|c|c|}
\hline & 活期 & 三个月 & 六个月 & 一年 & 两年 & 三年 \\
\hline 基淮利车 & 0.35 & 1.10 & 1.30 & 1.50 & 2.10 & 2.75 \\
\hline 工商银行 & 0.30 & 1.35 & 1.55 & 1.75 & 2.25 & 2.75 \\
\hline 衣业银行 & 0.30 & 1. 35 & 1.55 & 1.75 & 2.25 & 2.75 \\
\hline 中国银行 & 0.30 & 1. 35 & 1.55 & 1.75 & 2.25 & 2.75 \\
\hline 建设根行 & 0.30 & 1.35 & 1.55 & 1.75 & 2.25 & 2.75 \\
\hline 交通银行 & 0.30 & 1.35 & 1.55 & 1.75 & 2.25 & 2.75 \\
\hline 招商银行 & 0.30 & 1.35 & 1.55 & 1.75 & 2.25 & 2.75 \\
\hline 郳储銀行 & 0.30 & 1.35 & 1.56 & 1.78 & 2.25 & 2.75 \\
\hline 上海浪行 & 0.30 & 1.40 & 1.65 & 1.95 & 2.40 & 2.75 \\
\hline 浦发银行 & 0.30 & 1.40 & 1.65 & 1.95 & 2.40 & 2.80 \\
\hline 中信银行 & 0.30 & 1.40 & 1.65 & 1.95 & 2.40 & 3.00 \\
\hline 光大很行 & 0.30 & 1.40 & 1.65 & 1.95 & 2.41 & 2.75 \\
\hline 兴业蛝行 & 0.30 & 1.40 & 1.65 & 1.95 & 2.70 & 3.20 \\
\hline 民生浪行 & 0.30 & 1.40 & 1.65 & 1.95 & 2.45 & 3.00 \\
\hline 广发银行 & 0.30 & 1.40 & 1.65 & 1.95 & 2.40 & 3.10 \\
\hline 平安银行 & 0.30 & 1.40 & 1.65 & 1.95 & 2.50 & 2.80 \\
\hline 华夏银行 & 0.30 & 1.40 & 1.65 & 1.95 & 2.40 & 3.10 \\
\hline 北京浪行 & 0.30 & 1.40 & 1.65 & 1.95 & 2.50 & 3.15 \\
\hline 上海农商行 & 0.35 & 1.50 & 1.75 & 2.00 & 2.41 & 3.125 \\
\hline 宁波银行 & 0.30 & 1.50 & 1.75 & 2.00 & 2.40 & 2.80 \\
\hline
\end{tabular}

\begin{tabular}{|c|c|c|c|c|c|c|}
\hline 江苏蛝行 & 0.35 & 1.40 & 1.67 & 1.92 & 2.52 & 3.10 \\
\hline 杭州银行 & 0.30 & 1.43 & 1.69 & 1.95 & 2.52 & 3.08 \\
\hline 激海裉行 & 0.35 & 1.43 & 1.69 & 1.95 & 2.65 & 3.25 \\
\hline 天津银行 & 0.42 & 1.32 & 1.69 & 1.95 & 2.73 & 3.575 \\
\hline 浙商银行 & 0.35 & 1.43 & 1.69 & 1.95 & 2.50 & 3.00 \\
\hline
\end{tabular}

图1 部分商业银行各档期存款利率水平。
五大国有商业银行和招商银行这六家我国规模较大 的金融机构的存款利率保持一致, 三个月、六个月、一年 期定存利率均为 $1.35 \% 、 1.55 \% 、 1.75 \%$, 较基准利率上浮 0.25 个百分点, 两年期存款利率上浮约 $7 \%$, 三年期未上浮, 五年期与三年期利率相同。而部分城商行的存款利率上浮 力度较大，其中上海农村商业银行和宁波银行的三个月、 六个月、一年期定存利率为 $1.5 \% 、 1.75 \% 、 2 \%$, 分别较基 准利率上浮36\%、35\%、33\% , 上浮幅度位列各大商业银行 之首; 天津银行两年期和三年期的利率分别为 $2.73 \%$ 和 $3.575 \%$ ，成为商业银行同档期利率中的最高点。

从中也不难看出, 银行的存款利率水平 “抱团” 现象 较为明显, 利率定价科学化和精细化的程度较低。一些中 小银行为了拓展市场份额、防止存款流失, 只能通过提高 存款利率来应对。 [3]但是, 与大型商业银行相比, 中小 银行的信贷资产占总资产的比重相对较高, 其盈利能力更 多地倚重存贷利差, 因此利率的变动会对中小银行产生更 大的影响。

\section{2. 利率市场化对中小商业银行盈利能力影响的 分析}

\section{1. 对传统经营模式的影响}

利率市场化改变了金融体系结构, 促进了信托公司、 资产管理公司等相关机构的发展, 所以商业银行面临激烈 的行业竞争压力。[4]从国际经验来看, 银行为了突破发 展瓶颈, 纷纷改变传统的经营模式, 努力使收入呈现多元 化, 例如美国 “发行一分销” 经营模式、资产证券化以及 影子银行的发展。目前我国商业银行营业收入结构中, 利 息收入仍占有较高比例, 2015年16家上市商业银行平均利 息收入达到总收入的 $75 \%$, 随着利率市场化的推进, 盈利 空间压缩, 银行将会持续受到来自这一方面的压力。

\section{2. 对利率风险管理的影响}

利率市场化意味着利率水平将由资金的供需情况决 定，利率的波动将会更加频繁且难以预测。当短期利率与 长期利率波动幅度不一致时, 银行的利息收入将会减少, 因此银行必须根据利率缺口调整资产和负债的结构, 这会 造成银行资产收益和负债成本的不对称。另外, [5]由于 存贷款选择权在客户手中, 而利率波动会引发客户的道德 风险, 例如利率上升时, 客户有可能通过提前支取的方式 进行利率套利, 从而给银行造成利息损失。

\section{3. 对信贷资产质量的影响}

随着利率市场化的推进, 为了争夺客户资源, 中小商 业银行的存款利率会有所上升, 出于成本收益考虑, 也会 提高贷款利率，从而使信贷市场面临逆向选择风险。[6] 当银行提高贷款利率时，风险低的企业会首先从贷款市场 上退出, 选择其他方式比如债券等来获得资金; 而留给银 行的则是风险高的客户, 这时逆向选择就出现了; 另一方 面, 贷款利率提高之后, 企业融资成本增加, 为了获得收 
益企业很有可能会将贷款用于风险更高的项目, 于是又出 现了道德风险的问题。

\section{4. 加剧银行业的竞争}

在目前我国商业银行产品高度同质化的情况下, 放开 存款利率上限会进一步加剧存款争夺战, 容易形成银行间 的恶性竞争。随着互联网金融和其他非银行金融机构的飞 速发展, 银行在支付结算和理财方面的地位开始受到动摇, 如果为了扩张规模而盲目提高存款利率、降低贷款利率, 实力较弱的中小银行有可能面临亏损, 甚至倒闭, 造成整 个银行体系的不稳定，不利于金融市场建设。

\section{3. 实证分析}

\section{1. 样本选取及数据来源}

为了研究分析利率市场化对我国中小银行盈利能力 的影响, 本文选取我国8家股份制商业银行和3家城市商业 银行作为研究样本, 分别是招商、浦发、兴业、民生、华 夏、中信、平安、光大、北京、宁波和南京。样本数据的 时间范围定在 2008 年至 2015 年, 主要根据各银行的年报和 中国人民银行及国家统计局网站公布的相关数据整理而 得。

\section{2. 变量选取与定义}

由于具有高负债和高杜杆经营的特点, 使得净资产收 益率和每股收益率无法全面反映出中小商业银行的盈利 能力。因此, 我们选取总资产收益率 (ROA) 作为反映盈 利能力的指标, 其数值越大表明银行的盈利能力越强。

在自变量的选取上, 由于本文主要研究利率市场化对 商业银行盈利能力的影响, 因此引入净利差 (NIS) 作为 解释变量, 同时选择总资产规模( AT)、非息收入占比(UN)、 存贷比 (LDR) 和不良贷款率 (NPLR) 对中小银行的盈利 能力进行实证分析。

表1 变量名称及定义。

\begin{tabular}{|c|c|c|}
\hline 变量名称 & 变量符号 & 变量定义 \\
\hline 资产收益率 & $\mathrm{ROA}$ & 净利润/平均资产总额 \\
\hline 净利差 & NIS & （利息收入-利息支出）/总资产 \\
\hline 资产规模 & AT & $\begin{array}{l}\text { 由于数值过大, 因此将总资产取自 } \\
\text { 然对数后再进行分析 }\end{array}$ \\
\hline 非息收入占比 & UN & 非利息收入/营业总收入 \\
\hline 存贷比 & LDR & 贷款总额/存款总额 \\
\hline 不良贷款率 & NPLR & 不良贷款余额/贷款总额 \\
\hline
\end{tabular}

\section{3. 实证检验}

\section{3. 1 . 模型选择}

首先通过 Eviews8.0软件进行F统计量检验, 对样本 数据分别进行混合模型和固定效应模型回归, 根据回归结 果的 $\mathrm{F}$ 值来判断是选用混合模型还是个体固定效应模型。

$\mathrm{F}$ 检验的原假设与备择假设是:

$\mathrm{H}_{0}$ ：应建立混合回归模型

$\mathrm{H}_{1}$ ：应建立个体固定效应模型

$$
\mathrm{F}=(\mathrm{SSEr}-\mathrm{SSEu} / \mathrm{N}-1) /(\mathrm{SSEu} / \mathrm{NT}-\mathrm{N}-\mathrm{K})
$$

其中SSEr 是混合回归模型的残差平方和, SSEu是个体 固定效应回归模型的残差平方和, $\mathrm{T}$ 表示样本容量, $\mathrm{K}$ 表示 未加约束的模型中被估计参数的个数, ( $\mathrm{N}-1)$ 为混合模型 的模型约束个数, $(\mathrm{NT}-\mathrm{N}-\mathrm{K})$ 为固定效应模型的自由度。

\begin{tabular}{lrrr}
\hline $\begin{array}{l}\text { Redundant Fixed Effects Tests } \\
\text { Pool: HS }\end{array}$ & & & \\
Test cross-section fixed effects & & & \\
\hline \hline Effects Test & Statistic & d.f. & Prob. \\
\hline \hline Cross-section F & 5.716695 & $(10,103)$ & 0.0000 \\
Cross-section Chi-square & 53.420011 & 10 & 0.0000 \\
\hline \hline
\end{tabular}

图2 F检验结果。

F统计量的值为 $5.716695, \mathrm{P}$ 值小于 0.05 , 故拒绝原假 设, 应建立个体固定效应模型。然后需要通过Hausmen检 验来确定使用个体固定效应模型还是随机效应模型。

Hausman 检验的原假设与备择假设是：

$\mathrm{H}_{0}$ ：模型中个体的变化与解释变量不相关, 应建立随 机效应模型

$\mathrm{H}_{1}$ ：模型中不同个体的截距项Di不同，应建立个体固 定效应模型

Correlated Random Effects - Hausman Test
Pool: HS

Test cross-section random effects

\begin{tabular}{lrrr}
\hline \hline Test Summary & Chi-Sq. Statistic & Chi-Sq. d.f. & Prob. \\
\hline \hline Cross-section random & 11.714437 & 5 & 0.0389 \\
\hline \hline
\end{tabular}

图3 Hausmen检验结果。

从图中可知P值 $=0.0389<0.05$, 说明在 $5 \%$ 的置信水平 下, 应拒绝原假设接受备择假设。综合以上两项检验结果 得出: 建立个体固定效应模型对于研究分析本文的经济问 题是较为合适的。

\section{3.2. 模型估计}

基于上文的检验和分析, 我们使用Eviews8.0软件建 立个体固定模型，对11家上市中小商业银行 2008 年到 2015 年的样本数据进行回归, 结果如下:

\begin{tabular}{crrrr}
\hline \hline Variable & Coefficient & Std. Error & t-Statistic & Prob. \\
\hline \hline C & 0.659690 & 1.155278 & 0.571022 & 0.5698 \\
AT? & -0.005857 & 0.051881 & -0.112891 & 0.9104 \\
LDR? & -0.004358 & 0.005069 & -0.859696 & 0.3928 \\
NPLR? & -0.160324 & 0.063471 & -2.525936 & 0.0137 \\
NIS? & 0.305492 & 0.072541 & 4.211286 & 0.0001 \\
UN? & 0.014321 & 0.004639 & 3.087202 & 0.0029
\end{tabular}

图4 模型回归结果。

根据模型估计结果, 可以写出回归方程:

$\mathrm{ROA}=\mathrm{Di}+0.659690-0.005857 \times \mathrm{AT}-0.004358 \times$ $\mathrm{LDR}-0.160324 \times \mathrm{NPLR}+0.305492 \times \mathrm{NIS}+0.014321 \times \mathrm{UN}$ (2)

（其中Di为个体固定效应模型的截距项） 
表2 个体固定效应模型的截距项及模型P值。

\begin{tabular}{llll}
\hline 横截面个体 & 数值 & 横截面个体 & 数值 \\
\hline ZHONGXIN_C & 0.004649 & XINGYE_C & 0.036000 \\
GUANGDA_C & 0.045393 & ZHAOSHANG_C & 0.082029 \\
HUAXIA_C & -0.175478 & BEIJING_C & 0.130658 \\
MINSHENG_C & -0.045087 & NANJING_C & 0.149563 \\
PINGAN_C & -0.280366 & NINGBO_C & -0.054598 \\
PUFA_C & 0.107235 & Prob & 0.000000 \\
R-squared & 0.732616 & Adjusted & 0.701127 \\
\hline
\end{tabular}

从回归结果来看, $\mathrm{R}^{2}$ 和调整后的 $\mathrm{R}^{2}$ 分别为 0.732616 和 0.701127 , 说明模型的拟合度较好, P值无限接近于 0 , 说 明回归方程显著性较强。具体来看, 不良贷款率 (NPLR)、 净利差 (NIS) 和非息收入占比 (UN) 这三个变量在显著 水平 $\alpha=0.05$ 的情况下能够通过 $\mathrm{t}$ 检验, 说明它们对被解释 变量具有显著的影响; 而资产规模（AT）、存贷比（LDR） 对这11家商业银行盈利能力的影响并不显著。

\section{4. 实证结果分析}

\section{1. 资产规模}

资产规模 (AT) 的系数为 $-0.005857, \mathrm{P}$ 值为 0.9104 说明资产规模与中小商业银行盈利能力具有负相关性, 但 其影响并不显著。通常认为, 银行的资产规模越大, 其盈 利能力也越强, 但是对于中小银行来说这可能成为一个误 区。中小银行自身的资本实力较弱, 抗风险能力也不及大 型商业银行, 如果盲目增加贷款规模, 很有可能陷入利率 波动所带来的风险中, 因此中小银行更应该集中力量开展 非利息收入业务的拓展，在有效控制风险的基础上逐步提 高盈利能力。

\section{2. 存贷比}

方程中存贷比 (LDR) 的系数为 -0.004358 , 表明其与 资产收益率呈负相关, 这与中小银行的不良贷款有较为直 接的关系, 但P值为 0.3928 , 说明这一因素对银行盈利能 力并不能形成显著的影响。直观上理解商业银行存贷比指 标越高其盈利能力应该越强, 但是由于我国商业银行的存 贷比受到国家的严格控制, 变动幅度较小, 基本维持在一 个较为平稳的水平上, 因而其微小的变动并没有对商业银 行的盈利能力造成显著影响。

\section{3. 不良贷款率}

不良贷款率 (NPLR) 的影响系数为 -0.160324 , P值为 0.0137 , 表明不良贷款率对我国商业银行盈利能力有着较 为显著的负影响。一般来说, 不良贷款率较低, 银行的信 贷资产就会比较安全, 经营风险也较小, 相应的盈利水平 就会比较高。近几年来, 经济持续下行, 企业经营状况受 到很大影响, 行业性不良贷款率明显上升, 对中小银行造 成不小的压力。此外, 利率市场化以后, 银行间的竞争日 趋激烈, 中小银行更应严格控制风险, 确保资产的安全性。

\section{4. 净利差}

净利差 (NIS) 对资产收益率的影响系数为 0.305492 , $\mathrm{t}$ 统计量为 4.211286 , P值为 0.0001 , 说明净利差因素对中 小商业银行盈利能力有着显著的正向影响。但是在利率市 场化改革过程中, 存贷利差会明显减小, 商业银行的利润 空间被压缩, 传统的盈利模式必须改变。商业银行需要寻 求新的利润增长点, 创新业务产品, 逐渐将收入重点从存 贷利差转移到其他业务上, 在未来的几年中继续维持并提 升自身的盈利能力。

\section{5. 非息收入占比}

从实证结果可以看出, 非息收入占比 (UN) 的系数为 0.014321 , t值为 3.087202 , P值为 0.0029 , 说明非息收入 对中小商业银行盈利能力具有显著的正向影响。然而, 目 前在我国商业银行的收入结构中, 对盈利贡献最大的依然 是利息收入, 但是随着利率市场化改革的不断深入, 利差 收窄, 各银行盈利受到威胁, 使其不得不另寻出路, 因此 中小银行更应该抓住这个机会大力发展中间业务, 提升非 利息收入在银行利润中的占比, 从而提升竞争力, 强化盈 利能力。

\section{5. 中小商业银行应对利率市场化的建议}

\section{1. 完善定价机制, 注重人才培养}

虽然经过多年的发展, 我国上市中小商业银行已经初 步形成了分层定价机制, 但是仍然存在很多问题, 比如定 价方式单一粗放、管理体系不健全等, 难以适应利率市场 化改革的发展。因此, [7]银行应充分考虑自身的实际状 况, 根据本行的资产负债结构、网点结构布局、业务和盈 利模式、客户特点等具体情况, 制定利率市场化条件下的 经营策略、定价策略。同时, [8]商业银行要建立健全内 部控制制度, 加强内外部监管, 形成公开的、透明的产品 定价体系。其次, 应该重视相关金融衍生品的运用, 比如 利率期货、期权、互换等, 以此帮助银行有效规避由利率 波动所产生的风险。另外, 还应根据金融的发展趋势不断 吸收金融产品创新领域、互联网金融领域、计算机与大数 据分析领域的相关专业人才, 结合自身的实际情况, 建立 科学的培训体系, 为提高盈利能力打下扎实的人才基础。

\section{2. 发展中间业务, 实现多元化经营}

发达国家的商业银行尤其重视中间业务的开展, 经过 长期的业务创新其经营品种甚至可达上百种, 涉及管理、 担保、融资、财务顾问、衍生金融工具交易等众多领域。 我国商业银行的中间业务起步较晚, 目前占营业收入的比 重仍然比较小, 与发达国家相比有很大的差距。随着利率 市场化改革的深入, 存贷利差收窄, 商业银行所承受的利 率风险和信用风险将有所增大。因此, 中小银行应该转变 经营理念, 大力发展中间业务, 加快调整盈利模式和经营 战略, 实现多元化经营。[9] 同时充分发挥自身优势, 结 合国外商业银行和我国大型商业银行的成功经营, 积极开 
拓适合本行业务特点的中间业务, 明晰市场定位和服务重 点, 优化客户结构, 拓展利润空间。

\section{3. 控制不良贷款, 提高资产质量}

目前我国商业银行贷款业务的特点是前期审核较为 严格, 但是对于贷后管理并没有引起足够的重视。 [10] 商业银行应该建立相应的预警机制, 对可能出现的无法按 时偿还贷款的情况进行预判, 尽量做到提前处理, 最大程 度减少自身的损失。商业银行要建立有效的不良贷款核销 制度, 积极控制信贷资产质量, 健全风险约束机制。同时, 还应对坏账呆账准备进行科学化管理，对不良拆借资金、 无效投资、表外业务垫款和挂账案件损失等进行有效清理, 为银行的发展创造良好的经营环境。

\section{4. 紧随国家战略, 加快国际化推进步伐}

在国际化经营方面, 我国大型商业银行起步较早, 其 中中国银行的国际化程度最高, 从海外机构、人员、资产、 收入和利润指标来看都具有相当的优势, 其在海外业务经 营上具有很强的竞争实力。中小商业银行的国际化进程才 刚开始, 但招商、光大、浦发、平安、民生、中信等均体 现了对此的积极性, 包括在跨境领域的业务量增长, 参与 跨境支付系统, 拓展海外新机构等。未来随着人民币国际 化和一带一路战略的发展, 中小商业银行的国际化布局也 将逐步深化。

\section{6. 结论}

在利率市场化改革的进程中, 我国银行业必将面临来 自各个方面的影响和冲击。从国际经验看, 利率市场化后 商业银行的核心竞争力主要体现在两个方面: 一是多样化 的业务模式; 二是精准、灵活的利率定价能力。在此过程 中, 中小商业银行应该结合本行特点, 充分发挥自身优势, 积极创新业务品种, 努力改变银行产品同质化的现状, 通 过优质的服务吸引更多的客户资源。同时需要明确定位、
加快转型, 合理配置资产负债、调整收入结构、转变传统 盈利模式、建立和完善科学的定价体系、提高风险管理能 力, 确保自己能够在激烈的银行业竞争中占有一席之地。

\section{参考文献}

［1］钮文新. 利率市场化不等于利率自由化 [N]. 江苏经济报, 2015-11-18 (A01)。

［2］中国银行业协会利率工作委员会. 完全放开存款利率上限 对商业银行的影响及应对 [J]. 中国银行业, 2015, (12)： 51-54。

[3] 左峥, 唐兴国, 刘艺哲. 存款利率市场化是否会提高银行风 险一一基于存贷利差缩窄的一个视角 [J]. 财经科学, 2014, (2) : 20-29。

４］谭中明, 时红. 利率市场化对商业银行盈利能力的影响一 一以四大国有银行为例 [J]. 银行管理, 2015, (3) : 17-20。

[5] 王玉祥. 利率市场化条件下商业银行盈利模式研究 [J]. 商 场现代化，2016，（3）：111-112。

［6］李亮亮, 刘丞. 利率市场化对商业银行盈利能力影响因素的 作用 $[J]$. 金田，2013，（5）：345。

[7] 中国人民银行荆门市中心支行课题组. 利率市场化改革对 商业银行盈利能力的影响及对策——基于荆门市各金融机 构的实证分析 $[J]$. 金融纵横, 2015，（12）：44-47。

[8］陈希娟. 利率市场化下我国商业银行利率风险管理 $[\mathrm{J}]$. 金 融市场，2014，（47）：32-33。

［9］李菁楠, 任森春. 利率市场化背景下存贷利差对商业银行盈 利能力影响的实证研究-以上市银行为例 $[J]$. 长春理工大 学学报 (社会科学版)，2014，27（7）：90-93。

[10] 王瑞, 王家华. 利率市场化对国有商业银行盈利模式影响分 析 $[J]$. 海南金融, 2015，（6）：66-72。 